\title{
A Flipped Solid Mechanics Course Designed Based on the Interactive, Con- structive, Active, and Passive (ICAP) Framework
}

\section{Dr. Haolin Zhu, Arizona State University}

Dr. Haolin Zhu received her PhD in Solid Mechanics and Computational Science and Engineering from Cornell University. She is currently part of the freshmen engineering education team in the Ira A. Fulton Schools of Engineering at Arizona State University. Currently she focuses on designing the curriculum for the freshman engineering program as well as the NAE Grand Challenge Scholars Program. She also designs and teaches courses in mechanical engineering at ASU. Her interests include innovative teaching pedagogies for increased retention and student motivation, innovations in non-traditional delivery methods, as well as structured reflective practices throughout the engineering curriculum. 


\section{A Flipped Solid Mechanics Course Designed Based-on the Interactive, Constructive, Active, and Passive (ICAP) Framework}

Introduction

According to Lage et al., "Inverting the classroom means that events that have traditionally taken place inside the classroom now take place outside the classroom and vice versa"" The word flipped sometimes is also used for a classroom environment like this. A flipped (or inverted) classroom is getting a lot of attention in the engineering education world recently. Many authors have completely or partially flipped a course and many of them discussed the specific techniques used and/or the impact of this instruction mode, for example, Talbert discussed MATLAB taught in an inverted classroom format ${ }^{2}$; Gannod et al. talked about teaching software engineering using inverted classroom and podcasting ${ }^{3-4}$; Toto et al., flipped the work design in an industrial engineering course ${ }^{5}$; Zappe et al., implemented a flipped classroom model for active learning in an architectural engineering course ${ }^{6}$; Demetry discussed team-based learning in a flipped introductory materials science and engineering course ${ }^{7}$; Le et al., flipped an engineering dynamics class $^{8}$; Holdhusen talked about a flipped statics course ${ }^{9}$; Lee et al., flipped a mechanics of materials course ${ }^{10}$; etc., while others have partially flipped one ${ }^{11-16}$. Most of these flipped classroom models were related to student-centered learning theories, such as, active learning, peer-assisted learning, cooperative learning, collaborative learning, problem-based learning, peer tutoring, etc. ${ }^{17-22}$. However, in general, most of them have not followed any specific theoretical framework. This paper describes a flipped Solid Mechanics course that has been designed and taught during the Spring 2015 semester at Arizona State University, following the Interactive, Constructive, Active, and Passive (ICAP) framework by Chi et al. ${ }^{23}$.

According to Chi et al. ${ }^{23}$, engagement behaviors can be categorized into one of the four modes: passive, active, constructive, and interactive; and out of these four modes, students' learning increases when they are more engaged in course materials, from passive to active to constructive to interactive. Examples of passive learning include listening to a lecture; reading a book; and observing a video; etc. ${ }^{24}$. While active learning means students are actively manipulating course materials, for example, they write summaries of the text; take verbatim notes; copy solutions to example problems; pause, play, fast-forward, or rewind a tape; etc. ${ }^{24}$. Characteristics of constructive activities include new ideas being generated from outputs such as a concept map, a reflection report, self-generated notes, an explanation, etc. that go beyond what was presented ${ }^{23}$. Finally, being interactive means that students are interacting with others and each person involved needs to be constructive. Examples of interactive learning activities include, two students arguing and defending a position; two students asking and answering comprehension questions; etc. ${ }^{23}$. While the phrase "active learning" has been used a lot when one talks about a flipped classroom, there are different levels of "active learning" activities and a course that is designed to focus on more constructive and interactive learning activities will more likely enhance students' learning. 
In the following sections, the details of the design and implementation of the flipped Solid Mechanics course based on this ICAP framework will be discussed. Examples of learning activities that focus on each of the four modes of learning will be given. Challenges of designing a course using this framework will be addressed. Students' perception of this flipped course as well as its benefits will also be discussed based on both quantitative and qualitative results. More specifically, the flipped class has been used as the experimental group and the course taught by the same instructor in a previous semester using the traditional lecture-style is used as the control group. Students' performances on exams as well as the responses from the end-of-semester course evaluation surveys are compared between the two groups and both quantitative and qualitative results will be presented and discussed.

Course Overview

The Solid Mechanics course is a sophomore level 3-credit course required for all mechanical and aerospace engineering majors at Arizona State University. The class meets twice a week, for $75 \mathrm{~min}$ each time. It introduces the concepts of stress and strain, the stress-strain relation, and applications of force transmission and deformations in axial, torsional, and bending of bars. The core learning outcomes of this course are given in Table 1.

Table 1. Learning Outcomes of Solid Mechanics

\begin{tabular}{|l|l|l|}
\hline Course Core Outcome. & $\begin{array}{l}\text { ABET } \\
(\mathrm{a}-\mathrm{k})\end{array}$ & Level of Mastery \\
\hline $\begin{array}{l}\text { 1. Students will understand the definitions of stress and } \\
\text { strain, and basic mechanical properties of materials such as } \\
\text { elasticity, yielding stress, Young's modulus and Poisson's } \\
\text { ratio }\end{array}$ & $\mathrm{a}$ & Knowledge \\
\hline $\begin{array}{l}\text { 2. Students will apply concepts of strain and stress to the } \\
\text { analysis of statically-determinate (a) and indeterminate (b) } \\
\text { bars under axial loading }\end{array}$ & $\mathrm{a}, \mathrm{e}$ & Comprehension \\
\hline $\begin{array}{l}\text { 3. Students will apply concepts of strain and stress to the } \\
\text { analysis of statically-determinate (a) and indeterminate (b) } \\
\text { shafts in torsion }\end{array}$ & $\mathrm{a}, \mathrm{e}$ & Comprehension \\
\hline $\begin{array}{l}\text { 4. Students will analyze the shear, moment distribution, } \\
\text { and calculate stress in beams under bending }\end{array}$ & $\mathrm{e}$ & Comprehension \\
\hline $\begin{array}{l}\text { 5. Students will predict deflection in beams under } \\
\text { bending, and analyze statically indeterminate beams }\end{array}$ & $\mathrm{e}$ & \\
\hline
\end{tabular}


This course has been taught using the traditional lecture-style in the past. The flipped classroom model was implemented in one of the three sections of this course offered during the Spring 2015 semester taught by the author. 91 students were enrolled in this section during that semester.

Design and Implementation of the Flipped Course

All course materials were prepared during the summer of 2014. 25 lectures were first identified based on the five core learning outcomes as well as the sections of the textbook used (Mechanics of Materials by R.C. Hibbeler ${ }^{25}$ ). Topics of these lectures are shown in the table below.

Table 2. Lectures

\begin{tabular}{|c|c|c|}
\hline Lectures & Topic & $\begin{array}{c}\text { Core Learning } \\
\text { Outcome (refer to } \\
\text { Table 1) }\end{array}$ \\
\hline 1 & Review of Statics Concepts & N/A \\
\hline 2 & Distributed Loads & N/A \\
\hline 3 & Internal Loadings \& Method of Section & 1 \\
\hline 4 & Concept of Stress \& Average Normal Stress & 1 \\
\hline 5 & Average Shear Stress & 1 \\
\hline 6 & Concept of Strain & 1 \\
\hline 7 & Stress-Strain Diagram \& Hooke's Law & 1 \\
\hline 8 & Shear Stress-Strain Diagram \& Poisson's Ratio & 1 \\
\hline 9 & Elastic Deformation of Axially-Loaded Members & 2 \\
\hline 10 & Statically Indeterminate Axially-Loaded Members & 2 \\
\hline 11 & Thermal Stress & 2 \\
\hline 12 & Axially-Loaded Members Practice & 2 \\
\hline 13 & Torsion & 3 \\
\hline 14 & Angle of Twist & 3 \\
\hline 15 & Statically Indeterminate Torque-Loaded Members & 3 \\
\hline 16 & Beam Bending - Shear and Moment Diagrams & 4 \\
\hline 17 & $\begin{array}{l}\text { Beam Bending - Shear and Moment Diagrams } \\
\text { Graphical Method Part } 1\end{array}$ & 4 \\
\hline 18 & $\begin{array}{l}\text { Beam Bending - Shear and Moment Diagrams } \\
\text { Graphical Method Part } 2\end{array}$ & 4 \\
\hline 19 & Moment of Inertia & 4 \\
\hline 20 & Bending Stress & 4 \\
\hline 21 & Beam Deflection - Method of Integration & 5 \\
\hline 22 & Beam Deflection - Method of Superposition & 5 \\
\hline 23 & Statically Indeterminate Beams & 5 \\
\hline 24 & Beam Bending Practice & $4 \& 5$ \\
\hline 25 & Final Review & \\
\hline
\end{tabular}


For each lecture, activities around all four learning modes of ICAP were then selected. In general, each lecture has 1-3 short audio lectures that students were required to view before they came to the class; notes that summarize the key points; a group reading quiz that students took in groups at the beginning of the lecture; a worksheet that students worked on during the lecture in groups. In addition to these materials, a truss bridge design project has also been developed to provide extra hands-on design experience. This article will only focus on activities that were more relevant to the flipped course and details of this hands-on design project will be skipped here and they can be found in $\mathrm{Zhu}^{26}$. In terms of assessment of the course learning outcomes, in addition to the group reading quizzes, a total of five homework assignments (two problems each), each covering one of the five core learning outcomes were assigned. Three in-class preliminary exams as well as a final exam were also used.

\section{Audio Lectures}

Most flipped classes use pre-recorded videos as the pre-lecture materials. For this course, Livescribe $^{\mathrm{TM}}$ smartpen has been used to record audio on special notebooks that have Paper Replay $^{\mathrm{TM}}$ features. This results in Pencast ${ }^{\mathrm{TM}}$, an interactive set digital notes that allows the users to see, hear, and relive the notes exactly as they were captured. This Pencast ${ }^{\mathrm{TM}}$, instead of videos, has been selected because of its following benefits: from a faculty's standpoint, it is a lot easier to set up and use in a regular office setting without the need of a camera and/or a microphone and no post-processing is required; and it makes following the lectures, which are heavily diagrams and equations based easier for students. Students will be able to see the entire procedure as if they were watching an instructor writing notes on the board. Below is a screenshot of a Pencast ${ }^{\mathrm{TM}}$ file being played. The entire page of notes can be seen in gray and once the audio is played, one can see how the notes were developed as the notes turn green and hear the instructor talking. At the bottom of the page, one can also manipulate the audio file by pausing, replaying, fast-forwarding, rewinding, etc. 


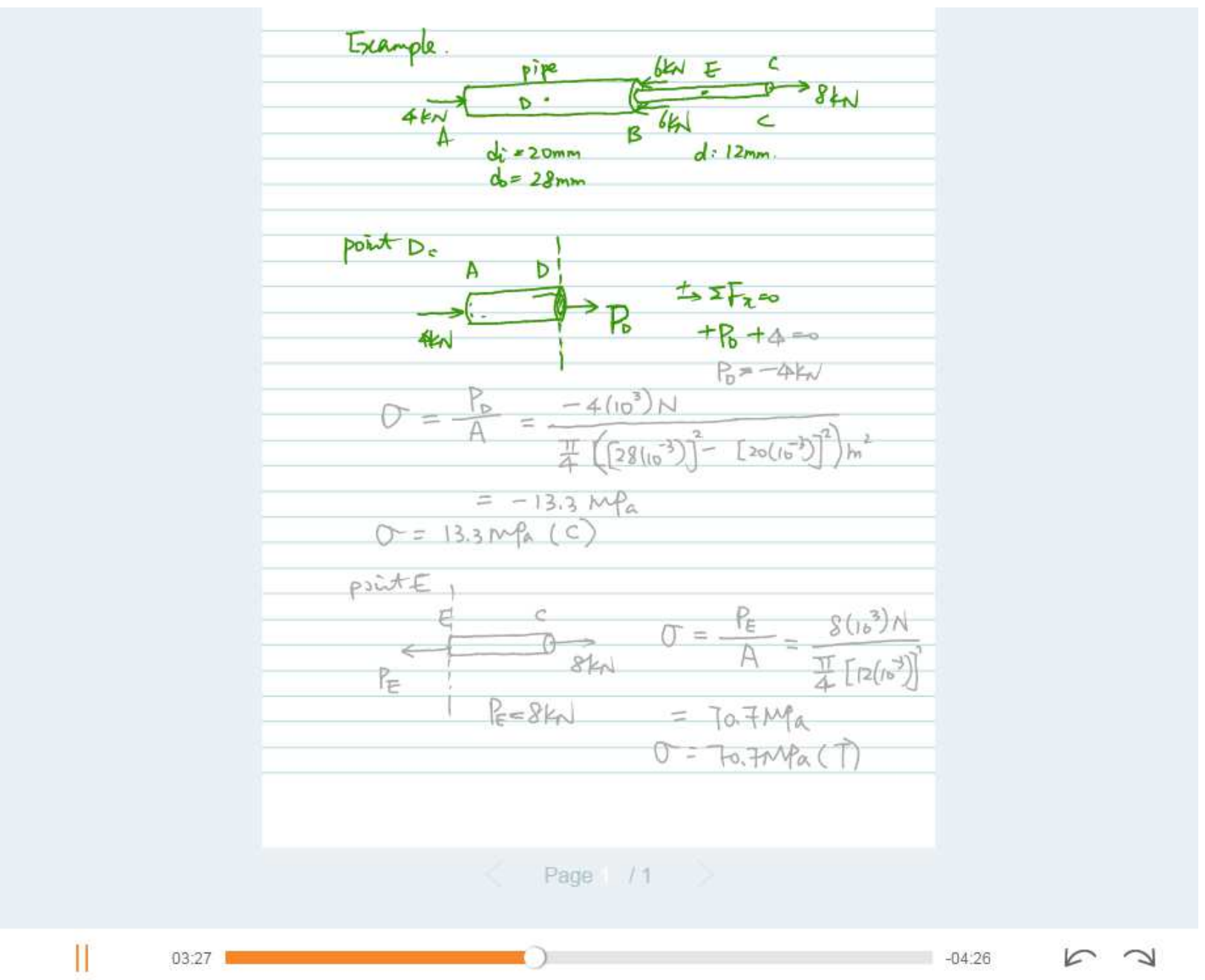

Figure 1. Screenshot of a Pencast ${ }^{\mathrm{TM}}$ file being played

Each lecture for this course contains 1-3 audio lectures, the shortest of which is 4 min long and the longest being $15 \mathrm{~min}$ long. Students were required to watch these audio lectures before they came to each class. They were also highly encouraged to manipulate them (pause, replay, etc.) as they feel necessary. 1-2 examples were also recorded for each lecture, but they were released to students after the class. Watching the audio lectures can be considered a passive learning mode and manipulating them is considered active. Both activities are low-level learning activities according to the ICAP framework and thus they were moved outside of the class and class time can be used for higher-level learning activities.

\section{$Q \& A$}

As students prepared for each lecture on their own, they were highly encouraged to post any questions they might have to the Piazza discussion board embedded in the Blackboard course site. They were also encouraged to write down the question(s) anonymously and drop the question(s) to the in-class drop box as they walk into the classroom for each class period. Questions posted to the Piazza discussion board were answered by the instructor, teaching 
assistants, and/or peers and ones that were common were addressed by the instructor at the beginning of each class period. Questions submitted to the in-class drop box were also answered by the instructor at the beginning of each class period. This Q\&A was used to promote constructive learning. However, as students were not required to submit questions and/or answers to the questions, this activity was only applicable to some of the students, those who submitted the questions and/or answers. In future offerings of this course, this activity could be modified to requiring students to submit either question(s) that they have or a summary of the key points using their own words for each lecture, making it constructive and applicable to all students.

\section{Student Groups}

Students were assigned to groups of three or four at the beginning of the semester. They stayed in the same group throughout the entire semester for the group reading quizzes, the in-class activities, as well as the truss bridge design project. To ensure interactive learning, groups were assigned based on students' familiarity with each other as well as their GPAs for the prerequisite courses. Those who used to study together and had similar GPAs were assigned to the same group. According to Chi et al. ${ }^{23}$, criteria for an interactive engagement are that, "(a) both partners' utterance must be primarily constructive, and (b) a sufficient degree of turn taking must occur" ${ }^{23}$. Thus, if high achieving students were paired with low achieving students, it is more likely that the second criterion would be violated as it is more likely that the high achieving students would dominate the conversation for in-class activities. Thus, the way the groups were set up was meant to promote interactive learning activities in class.

\section{Group Reading Quizzes}

To hold students accountable for the pre-lecture learning, group reading quizzes (each contained two questions) were used at the beginning of the classes to test if students had viewed the audio lectures and to check students' basic understanding of the concepts. Students took the quizzes in groups at the beginning of each class period and they were allowed to discuss the questions.

Group reading quizzes rather than individual quizzes were used because interactive learning mode was promoted as this allows students to actively discuss and debate the answers. When a quiz is individual based, each student will generate answers on their own and the learning mode is considered constructive, which is at a lower level compared to interactive. To ensure active participation from all members in each group and to promote the "taking turns" nature of being interactive, peer evaluations were used for each quiz, the results of which were then factored into each individual's quiz grade.

\section{Worksheets}

Rather than just having students work on homework problems during the classes, in-class practice problems were carefully selected and/or designed and in-class worksheets were developed for all the lectures. Students were required to discuss the worksheet problems in groups but the writing must be each student's own work and they were required to submit the 
completed worksheets individually. These worksheets were not graded for credit but students were able to earn engagement points for producing quality work. The details of the engagement points will be discussed in the following section.

In some of the flipped classroom models, part of the lecture time was still used for reviewing and/or examples explanation, i.e., the instructor would still use some of the lecture time "lecturing", for example, Holdhusen spent time working out two examples in class and gave students the rest of the time to work on two other similar problems ${ }^{9}$. In such cases, students have seen worked out examples on the topic before they practiced working on problems on their own. In our flipped classroom model, most of the lecture time was dedicated to constructive and interactive learning activities, i.e., minimum amount of "lecturing" was present. A maximum of 5 minutes was spent by the instructor each class to address the questions submitted to the in-class drop box and/or to the Piazza discussion board. In addition, no examples were shown to students before the classes and students were thus forced to engage in active discussions when they worked on the worksheet problems, fostering interactive learning. When students had seen a similar problem being worked out, they may just follow the procedure, without thinking deeply about the "how" and the "why", and they may be less motivated to come to the classes and to discuss the problems with their peers. To further motivate discussions during the classes, these worksheets were not made available to students before the classes so that the problems were "new" to students and they were expected to struggle with (some of) them to a certain extent.

Each worksheet consists of four problems, with increasing levels of difficulty. The first problem is usually more basic and sometimes more conceptual. An example of this type of problem is given below.

Ex: Based on the definition of average normal stress \& average normal strain, and Hooke's law, can you express the deformation of the bar, $\delta$, in terms of its original length, L, cross-sectional area, A, material Young's Modulus, $E$, and the load, P? Assume that the material is linear elastic.

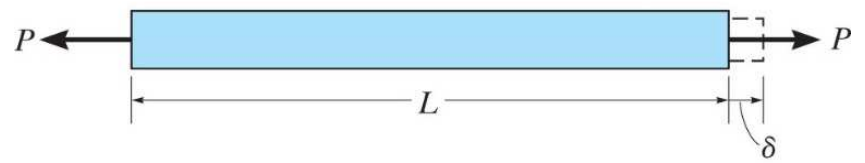

Figure 2. The first worksheet problem for the lecture Stress-Strain Diagram \& Hooke's Law (the figure is adopted from the textbook ${ }^{25}$ )

The second problem is usually a traditional textbook homework type of problem. The first two problems are included to help students better understand the basic concepts and to be able to apply them at a comprehension level.

The third one is more involved: some of them require additional thinking and are more difficult, while others involve everyday examples and/or hands-on aspects. Below are examples of the third problems on the worksheets: 
Ex: A high-strength concrete driveway slab has a length of $20 f t$ when its temperature is $20^{\circ} \mathrm{F}$. There is a gap of 0.125 in. on one side. The concrete has a material property of $\alpha=6\left(10^{-6}\right) /{ }^{0} \mathrm{~F}$. Could the gap be closed during summer if the house is located in Tempe? Create a model for this problem and justify your answer.

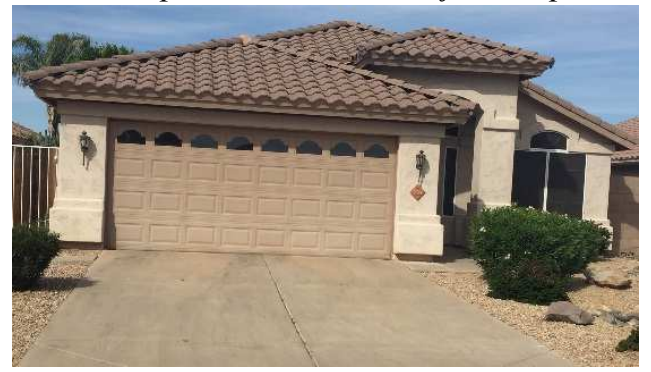

Figure 3. The third worksheet problem for the lecture Thermal Stress

Ex: An iPod, with a mass of 30 grams is dangled from its earplug cable. The cable consists of a copper wire (diameter: $0.40 \mathrm{~mm}, E=110 \mathrm{GPa}$ ) and a hollow insulation material $u P V C$ (outer diameter: $1 \mathrm{~mm}, E=2 \mathrm{GPa}$ ). The wire is $1.5 \mathrm{~m}$ long. Assume that both the copper wire and the insulation are bonded together and will both carry the

weight of the iPod. What would be the axial load in the copper wire and what about the plastic insulation?

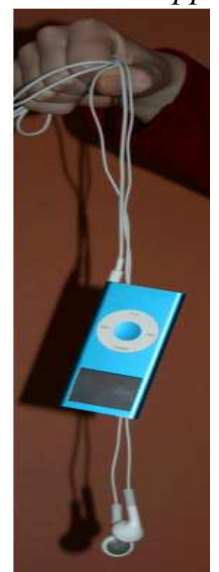

Figure 4. The third worksheet problem for the lecture Statically Indeterminate Axially-Loaded Members (problem was adopted from the ENGAGE website ${ }^{27}$ )

Ex: Approximately how much torque do you need to apply to the screw top in order to open the bottle of wine? The screw top is made of an aluminum alloy with a fracture stress of 240MPa in shear. (Note that a few empty wine bottles that had screw tops as well as a few digital calipers were brought to the classroom.)

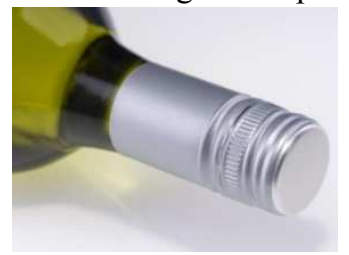

Figure 5. The third worksheet problem for the lecture Torsion (problem was based on an example from the ENGAGE website ${ }^{27}$ )

Ex: How would you model this problem as a beam problem? What assumptions do you need to make and what information do you need? Draw the shear and moment diagrams. (Note that a teaching assistant was asked to ride 
the skateboard in class as a demonstration. And the following picture was provided. Tape measures were made available in the classroom.)

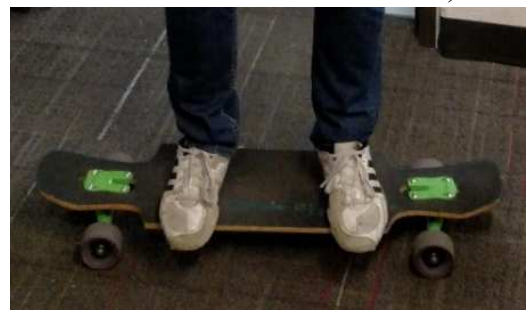

Figure 6. The third worksheet problem for the lecture Bending Shear and Moment Diagrams (problem was based on an example from the ENGAGE website ${ }^{27}$ )

The fourth problem is usually more challenging. Some of the fourth problems involve concepts that are related to the lecture topic but were not introduced at the time the problem was given, while others require synthesis of information. Below are some examples:

Ex: The rigid beam rests in the horizontal position on two 2014-T6 aluminum ( $E=73.1 G P a)$ cylinders having the unloaded length shown. Each cylinder has a diameter of 30mm. For the beam to remain horizontal, where should the $80 \mathrm{kN}$ load be applied, i.e., what should the placement $x$ of the applied $80-k N$ load be in order for the beam to remain horizontal? (Note that statically indeterminate problems had not been introduced when the problem was given.)

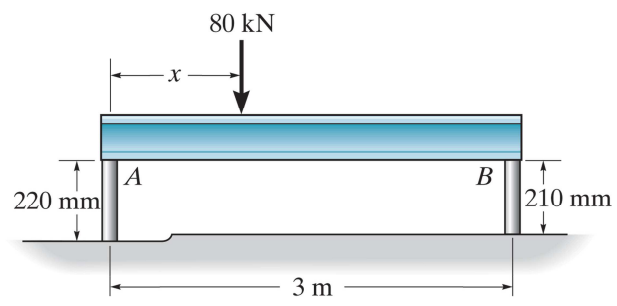

Figure 7. The fourth worksheet problem for the lecture Stress-Strain Diagram \& Hooke's Law (the figure is adopted from the textbook ${ }^{25}$ )

Ex: How many bolts are needed to make the maximum shear stress in the shaft due to torsion equal to the average shear stress on the cross section in each of the bolts? Each bolt has a diameter of d.

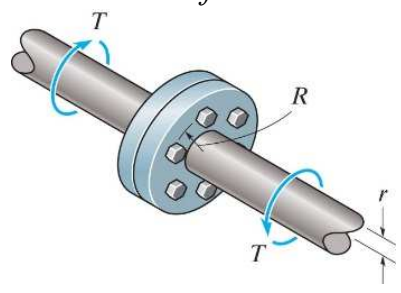

Figure 8 . The fourth worksheet problem for the lecture Torsion (the figure is adopted from the textbook ${ }^{25}$ )

Ex: For the following beam problem, (a) determine the support reactions; (b) draw the shear and bending moment diagrams; (c) determine the absolute maximum bending stress. The beam cross section consists of two w8x31 welded together (one on top of the other). $w=2 \mathrm{kip} / \mathrm{ft} ; L=10 \mathrm{ft} ; E=29\left(10^{3}\right) \mathrm{ksi}$. 


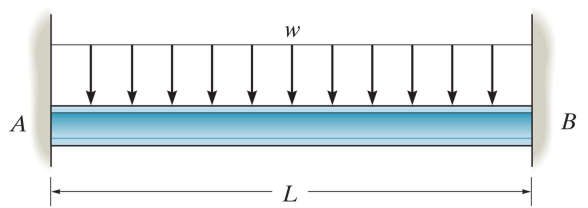

Figure 9. The fourth worksheet problem for the lecture Beam Bending Practice (the figure is adopted from the textbook ${ }^{25}$ )

According to Table 1, all of the core learning outcomes for this course are at either knowledge or comprehension level. This means that students are only required and expected to be able to recall some information and/or work on problems that are similar to the textbook problems. Thus, problems like the first two problems on each worksheet should have been sufficient to prepare students to meet these learning outcomes. However, the third and the fourth problems on the worksheets were chosen to be included due to the following reasons. For one, there were high achieving groups, i.e., groups of students who had higher GPAs in the prerequisite courses. Problems like the first two may not be able to keep these students engaged during the classes. For another, everyday examples and hands-on learning have been proven to have many benefits to students learning. For example, everyday examples in engineering are effective among all groups of students; they are relevant and familiar to students and thus increase student engagement and retention of engineering students; they highlight simple and complex ways that engineers help society ${ }^{27-32}$. Last but not least, to help students explore what they are capable of and feel more fulfilled, the instructor believes that students should be challenged.

\section{Undergraduate Teaching Assistants and Incentives}

For this class of 91 students, four undergraduate teaching assistants (UGTAs) who have taken the course before were utilized for in-class activities. Weekly meetings were held to prepare the UGTAs for the classes. They were given detailed solutions to the worksheet problems and were given instructions and guidance on how to ask the right questions to promote critical thinking; how to answer students' questions without giving the answers; and how to interact with students during the classes. During the classes, the instructor as well as all four UGTAs were present (approximately 1 to 18 teaching staff to student ratio or 1 to 5 teaching staff to student group ratio). The instructor talked to each and every one of the students during each class period and the UGTAs were also required to interact with as many students as possible. Through these interactions, constructive and interactive learning was facilitated. For example, when a student asked a question, a teaching staff would ask another question to help the students generate something new on his/her own, making the learning constructive; or the teaching staff would throw a question or questions at his peers in the group to foster discussions, making the learning interactive.

Tor further motivate students to interact with the teaching staff and to actively engage in class activities, an incentive based system was implemented. Each student was able to earn engagement points for attending a lecture and participated; for interacting with a teaching staff during a lecture; and for doing quality work with the worksheets. Engagement cards, each worth two points, were handed to students who have earned the points, and collected at the end of each 
class after students wrote their names on the cards. Total points that each student has earned, as well as the class maximum \& mean to date were released to students at the end of each week. The total number of engagement points that a student may earn was unlimited. At the end of the semester, all points were normalized to factors very close to 1: a factor that is greater than 1 was assigned to a student who has earned more points than the class mean; on the other hand, if the points were lower than the class mean, the student had a factor smaller than 1 . These factors were used to adjust students' final course grades. For example, for someone who has earned an $89 \%$ at the end of the semester and a factor of 1.02 , the final course grade was calculated as $89 \%$ times 1.02 (which equals $90.78 \%$ ), resulting in an A instead of a B in the course for the student.

\section{Challenges}

Designing and implementing a flipped class with higher level learning activities is very challenging. First of all, it has been a time consuming task. An overall structure had to be chosen first which would support the maximum amount of constructive and interactive learning. The instructor then spent about 2 days on average to prepare materials for each lecture. This includes recording the audio lectures and examples, developing notes, developing the group quizzes and solutions, designing and selecting problems for the worksheets and coming up with solutions as well as guided questions for UGTAs, etc. Another challenge was selecting or designing appropriate third and fourth problems for the worksheets. Finding everyday examples as well as hands-on learning opportunities for each topic was not easy. Logistically, it was very difficult to find a room which supports interactive learning for such a large class. The class was scheduled in a large lecture hall with staircase. It has proven to be very difficult for students to work together in groups and for the teaching staff to walk around when interacting with students. In addition, more effort was required for the instructor to manage the teaching team. In addition to the four UGTAs, a grader was utilized to help grade the homework assignments and the group quizzes, check all the worksheets, total and keep track of the engagement points, etc. Since they were all undergraduate students, providing the guidance for them to be able to facilitate constructive and interactive learning during the class was essential to the success of this model. Another big challenge was to "convince" the students that this model would likely benefit them more than a traditional lecture-style class. Most of them were used to traditional lecturing and thought it was the instructor's responsibility to teach (i.e., to lecture) during the lecture. Some of them thought that with this model, they were the ones doing all the work while the instructor did not do anything. The first lecture was very important for student motivation and it is suggested that a good amount of time be spent during the first lecture to introduce the model and to motivate the students.

\section{Outcomes}

Overall, this model has been very successful. The same instructor has also taught this course during Spring 2014 using the traditional lecture style. The Spring 2015 class (flipped) has been used as the experimental group and the Spring 2014 class (traditional lecture-style) is used as the control group. Students' performance on the three prelim exams from both groups are compared. 
Due to the fact that a hands-on design project was also implemented during Spring 2015, the final course performance is not compared. In addition, the end-of-semester course evaluation survey results are compared for both groups. Qualitatively, students' comments about the course when the flipped classroom model was utilized are coded and analyzed. All of these results are discussed below.

The three in-class preliminary examinations covered the same topics and had the same level of difficulty for both groups. Thus, students' performance on these examinations is compared. In the figures shown below, percentages of students in each of the following grade ranges are shown and compared for both groups: A (above 90\% on the exam); B (between $80 \%$ and 89.9\%); C (between 70\% and 79.9\%); D (between 60\% and 69.9\%); and E (below 60\%). For prelim exam I, similar distributions are found in the B, C, and D ranges for both groups, however, many more students earned an $\mathrm{A}$ in the experimental group. And the results are similar for prelim exam III. For prelim exam II, a greater portion of students were in the B range from the experimental group compared to that from the control group. It is interesting to note that for all three exams, a lot less students were found in the E range in the experimental group. This might indicate that this flipped classroom model has better helped low-achieving students and it helped those who would otherwise fail the class to successfully complete the class. This effect requires further investigation. One could conclude though that the flipped classroom style did not hurt students' performance.

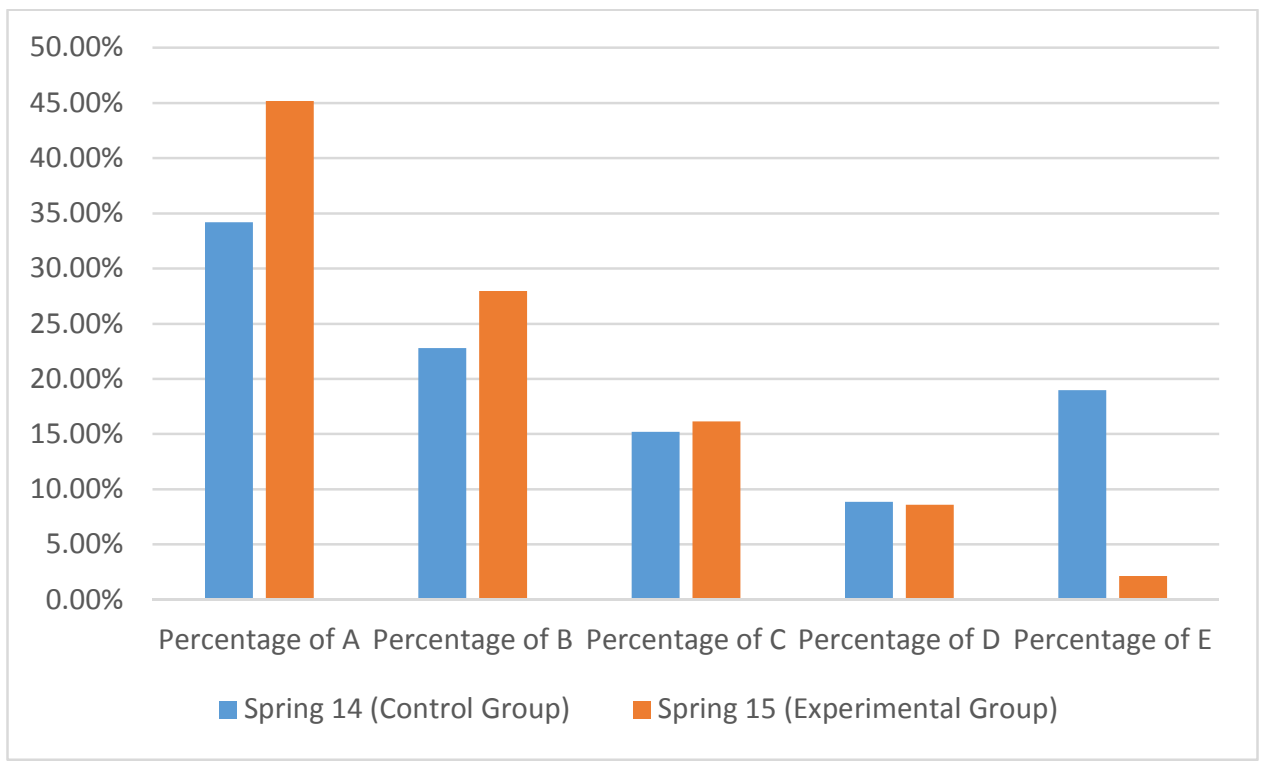

Figure 10. Prelim exam I results from both classes 


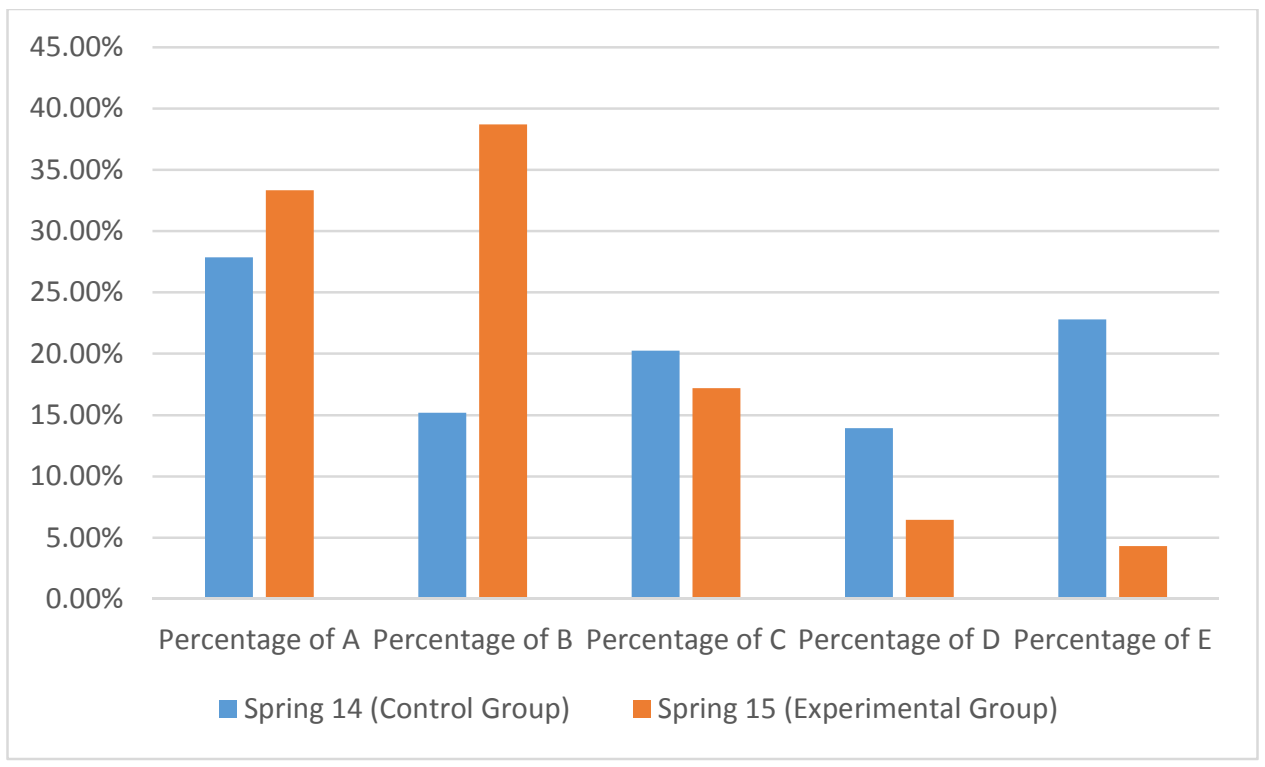

Figure 11. Prelim exam II results from both classes

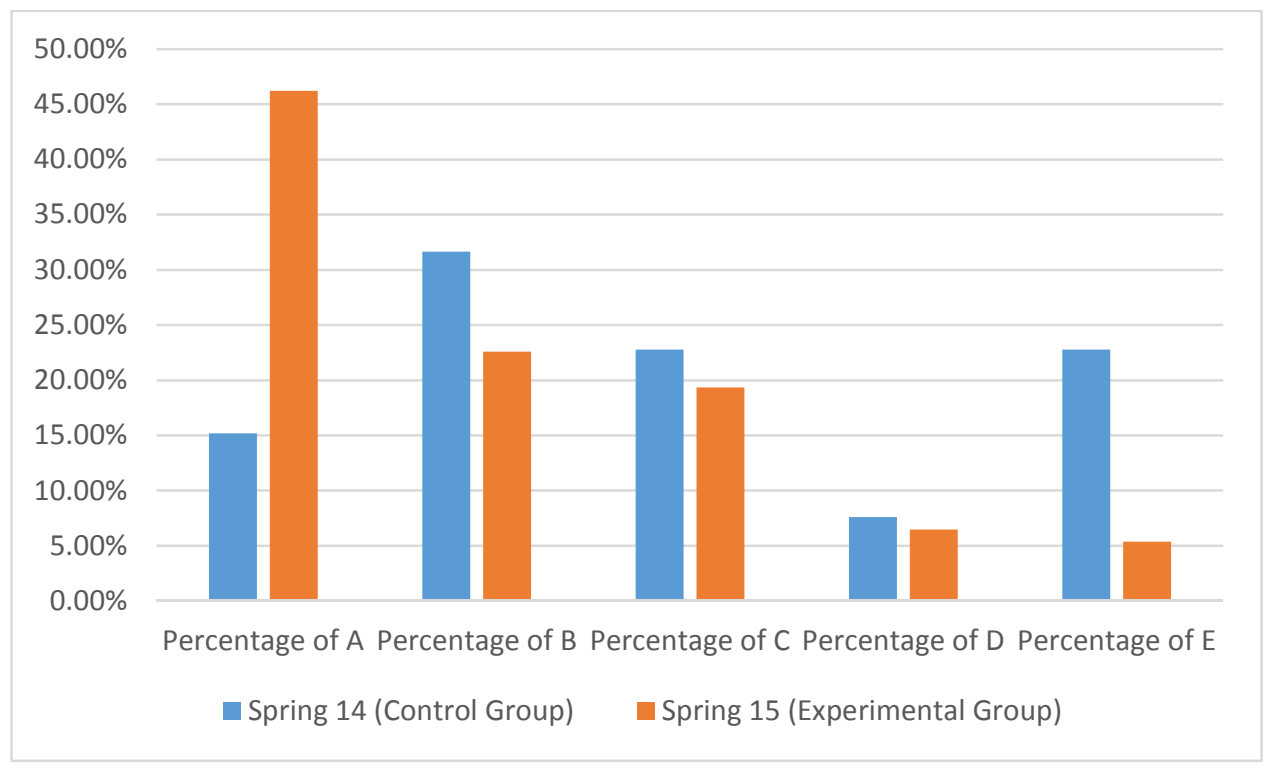

Figure 12. Prelim exam III results from both classes

The end-of-semester course evaluation survey was administered by the university during the last two weeks of classes. Students were notified about this via email and answers were collected anonymously and voluntarily. Students were highly encouraged to complete the survey and reminders were sent via email on a daily basis by the university. There were 16 questions on the survey and answers were collected using a Likert scale of 1-5 (1-almost never/poor; 5-almost always/very good). Some of the survey questions do not give useful information about the flipped classroom model, for example, "Textbook in support of the course"; "Value of assigned homework in support of course topics"; "Reasonableness of exams and quizzes in covering course material"; "Weight given to labs or projects, relative to exams and quizzes"; etc. Only 
five questions from the survey are selected to gain insights of students' attitudes about this flipped classroom model and the results are presented in the figure below. The spring 2014 class (traditional lecture-style) is again considered the control group (shown in blue) and the flipped one from spring 2015 is the experimental group (shown in orange). The response rate of the control group was $35.37 \%(\mathrm{n}=29)$ and that of the experimental group was $54.65 \%(\mathrm{n}=47)$.

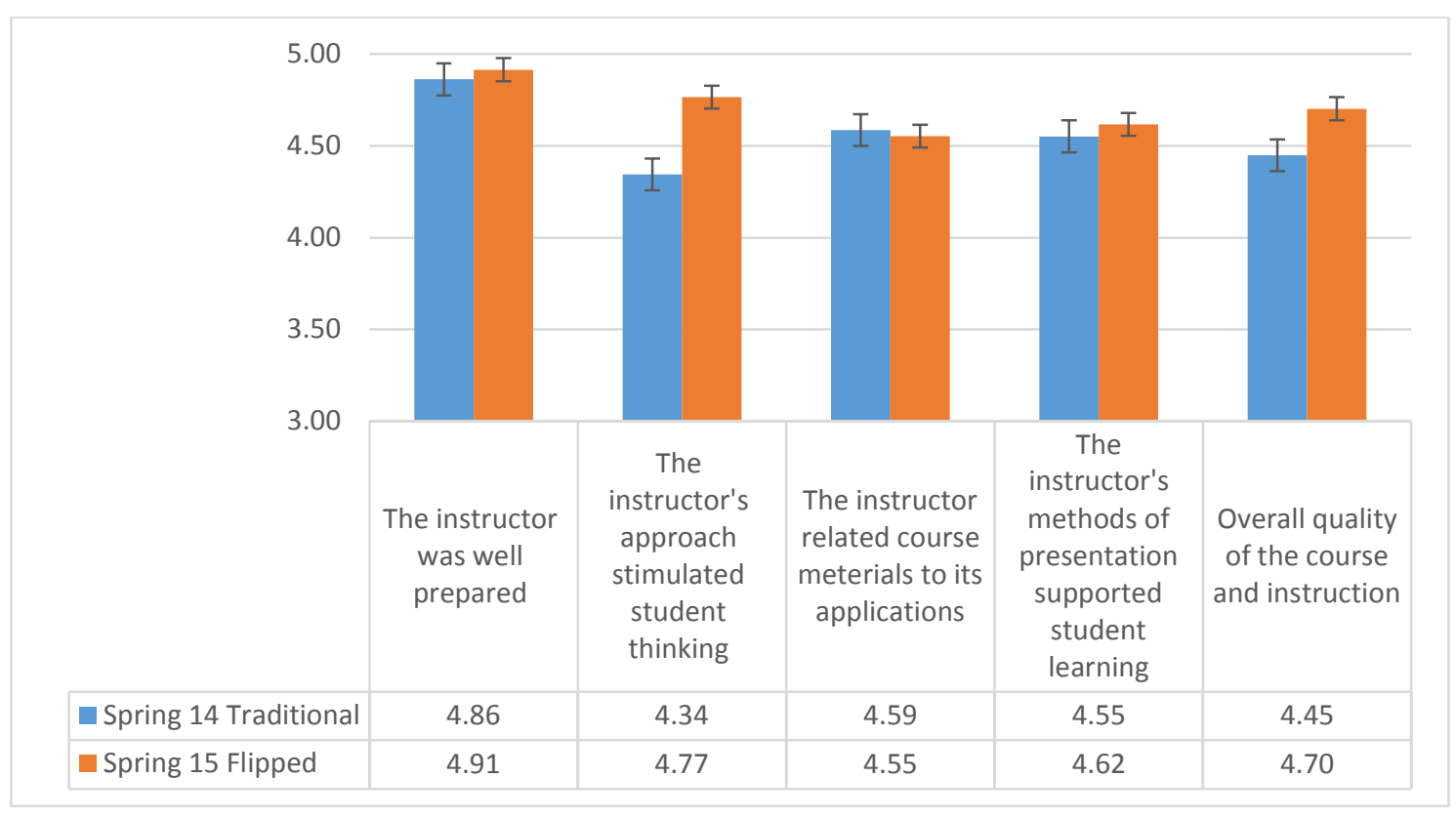

Figure 13. End-of-semester course evaluation survey results

Significant difference has been found for the following two survey questions between the two groups: "The instructor's approach stimulated student thinking" and "Overall quality of the course and instruction" $(p<0.05)$. And for both questions, the experimental group showed much higher mean scores. Based on the results, it is found that even though some students from the flipped class expressed negative feelings at the beginning of the semester and thought that the instructor did not do much (due to not lecturing), in the end, most students felt that the instructor was well prepared. Both groups did not think very differently about the teaching method. They both thought that the approach, either the traditional lecture-style or the flipped style, has supported student learning. However, the flipped method was a clear winner in helping stimulate student thinking. For the traditional approach, students were only challenged outside of the class when they worked on the homework assignments. Using the flipped model, on the other hand, students were forced to think about the concepts, how they were applied in different scenarios, etc. during each and every class period throughout the semester. Students in the flipped class also felt more positively about the course and instruction in the end as they rated the overall quality of the course and instruction higher compared to the traditional lecture-style group. It is also interesting to note that more students in the flipped class group were motivated to complete the survey even though no incentives were given for participation. 
One of the survey questions asked students to report the average number of hours spent studying for this course per week. Choices for this question given were: 1, 2, 4, 8, 16 hours. The figure below compares the results for this question between both groups. It can be seen that on average, students in the flipped class spent less amount of time studying for this course. $27.59 \%$ of students spent more than 8 hours on average each week on this course in the traditional lecturestyle class while the number was only $14.89 \%$ for the flipped class. On the other hand, 36.17\% of students in the flipped class spent less than 4 hours per week, while the number was only $10.34 \%$ for the traditional lecture-style class. This may be due to the fact that more learning was going on during the classes and students were able to study more efficiently using the flipped classroom style.
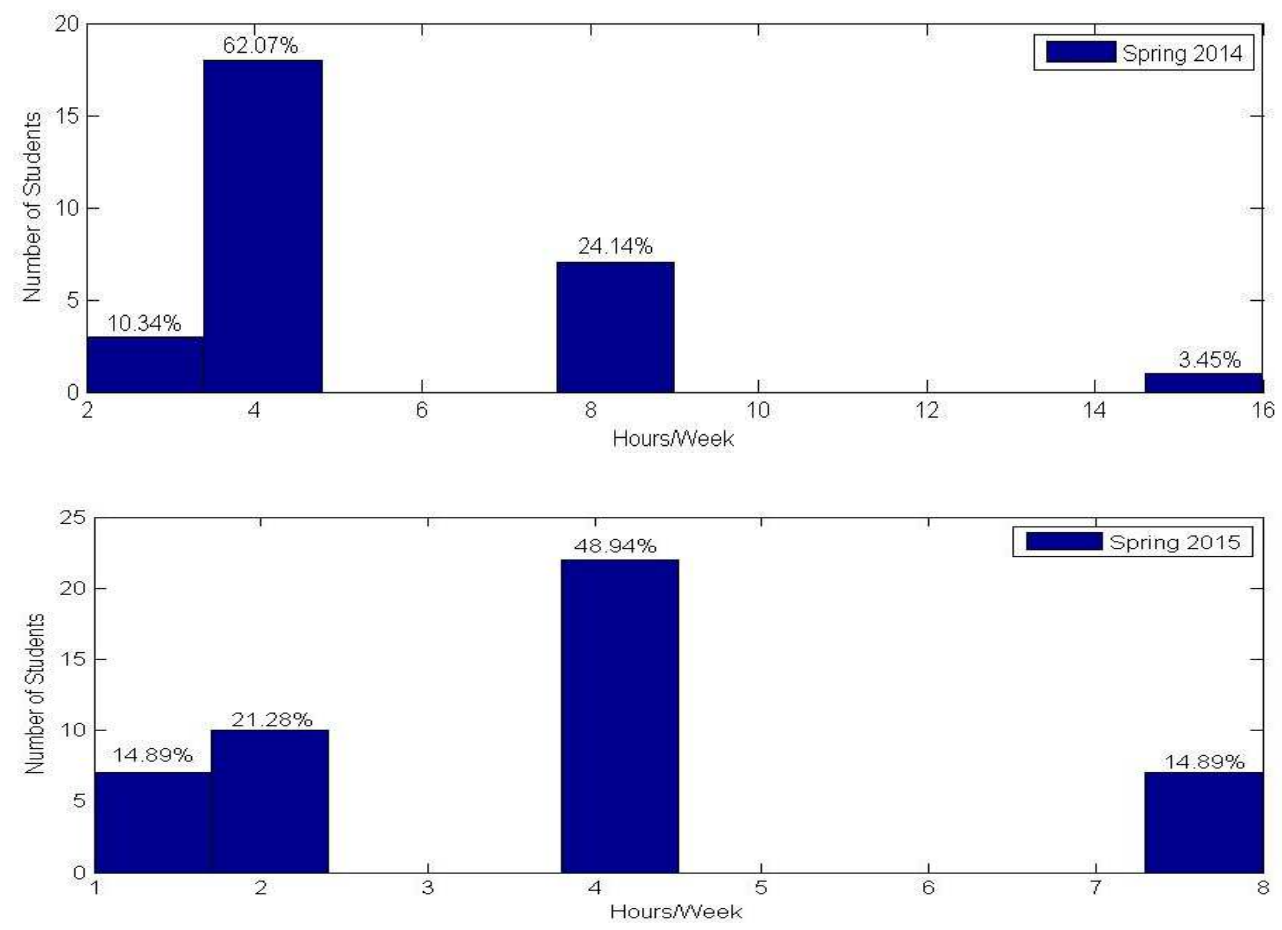

Figure 14. Average hours spent per week by students studying for this course

The qualitative results to follow represent students' free responses in the comments section of the end-of-semester course evaluation survey for the flipped class. All the comments have been coded and grouped into different themes. Based on the comments, again, it can be seen that overall students felt very positively about this instruction method. They thought that the flipped classroom structure helped support student learning in many ways. For example, 59.57\% of those who completed the survey from the flipped class mentioned that the flipped class model was very effective. $17.02 \%$ commented that this instruction method made learning easier for students and helped them gain a deeper understanding of the course materials. Some also mentioned other benefits of this method, including being able to receive support from both instructors/TAs and peers immediately when needed and being able to learn at one's own pace. Table 3 shows some examples of students' comments in each of the different theme areas. 
Table 3. Students' comments regarding the flipped course

\begin{tabular}{|c|c|c|}
\hline Theme & Example Reponses & Frequency \\
\hline $\begin{array}{l}\text { Effectiveness of the flipped } \\
\text { classroom model }\end{array}$ & $\begin{array}{c}\text { "Flipped classroom model works excellently for this } \\
\text { material." } \\
\text { "The flipped classroom that the instructor utilized in this } \\
\text { course was perhaps one of the best decisions I have seen in a } \\
\text { classroom." } \\
\text { "Flipped classroom is incredibly effective." }\end{array}$ & 28 \\
\hline $\begin{array}{l}\text { Helpfulness of the in-class } \\
\text { worksheets }\end{array}$ & $\begin{array}{c}\text { "The worksheets were helpful in understanding and applying } \\
\text { lecture concepts. They acted as examples and practice } \\
\text { problems and allowed us to avoid what I could see as being } \\
\text { some boring lectures." }\end{array}$ & 8 \\
\hline $\begin{array}{l}\text { Deeper understanding of } \\
\text { the materials and easiness } \\
\text { to learn }\end{array}$ & $\begin{array}{l}\text { "The upside-down class structure made learning much } \\
\text { easier." } \\
\text { "I feel like I have a more complex understanding of the } \\
\text { material, because I had worked the problems out and solved } \\
\text { out specific issues with fellow students." } \\
\text { "The instruction was excellent and the information was } \\
\text { presented in a way that made the concepts easy to understand } \\
\text { and master." }\end{array}$ & 8 \\
\hline $\begin{array}{l}\text { Availability of instructors } \\
\text { and TAs for questions }\end{array}$ & $\begin{array}{c}\text { "Being able to ask questions while working out problems in } \\
\text { class is very beneficial for learning the material well." } \\
\text { "I liked working among my friends in the class and having the } \\
\text { one-on-one Q \& As with the TA or the professor in the } \\
\text { classroom." }\end{array}$ & 6 \\
\hline $\begin{array}{l}\text { Building a relationship } \\
\text { with peers }\end{array}$ & $\begin{array}{l}\text { "The method of presentation allowed us to build relationships } \\
\text { with our peers." }\end{array}$ & 3 \\
\hline $\begin{array}{l}\text { Being able to learn at one's } \\
\text { own pace }\end{array}$ & $\begin{array}{c}\text { "I learned better, was more engaged, and overall learn better } \\
\text { from online lectures that are being written in real time by the } \\
\text { professor, with the ability to pause and go back to solidify } \\
\text { material in my head." }\end{array}$ & 3 \\
\hline
\end{tabular}

\section{Conclusion}

A flipped classroom model was designed based on the Interactive, Constructive, Active, and Passive (ICAP) framework. The course structure as well as various class activities were designed to promote higher level learning, i.e., constructive, and interactive learning. The model was implemented in the Solid Mechanics course taught during Spring 2015 semester. Both quantitative and qualitative results show that it worked well and has benefited students in many ways, including stimulating students thinking, enabling deeper understanding of the class material, increased interaction with instructor, being able to learn at one's own pace, less time spent outside of class learning the materials, etc. 


\section{References}

[1] Lage, M. J., Platt, G. J., and Treglia, M., "Inverting the Classroom: A Gateway to Creating an Inclusive Learning Environment", in The Journal of Economic Education, 31(1):30-43, 2000.

[2] Talbert, R., "Learning MATLAB in the Inverted Classroom", in American Society of Engineering Education Annual Conference \& Exposition, the Proceedings of, San Antonio, TX, 2012.

[3] Gannod, G.C., "WIP: Using Podcasting in an Inverted Classroom", in IEEE Frontiers in Education, Proceedings of, Milwaukee, WI, 2007.

[4] Gannod, G.C., Burge, J.E., and Helmick, M.E., "Using the Inverted Classroom to Teach Software Engineering", in the 30th International Conference on Software Engineering, Proceedings of, pages 777-786. ACM, 2008.

[5] Toto, R., and Nguyen, H., "Flipping the Work Design in an Industrial Engineering Course", In Frontiers in Education Conference, Proceedings of, San Antonio, TX, 2009.

[6] Zappe, S., Lieicht, R., Messner, J., Litzinger, T., and Lee, H.W., ""Flipping" the Classroom to Explore Active Learning in a Large Undergraduate Course", in American Society for Engineering Education Annual Conference \& Exposition, Proceedings of, Austin, TX, 2009.

[7] Demetry, C., "Work in progress: An Innovation Merging "Classroom Flip" and Team-Based Learning", In Frontiers in Education Conference, Proceedings of, Arlington, VA, 2010.

[8] Le, X., and Ma, G. G., "Testing the Flipped Classroom Approach in Engineering Dynamics Class", in American Society of Engineering Education Annual Conference \& Exposition, Proceedings of, Seattle, WA, 2015.

[9] Holdhusen, M. H., "A "Flipped" Statics Classroom", in American Society of Engineering Education Annual Conference \& Exposition, Proceedings of, Seattle, WA, 2015.

[10] Lee, L. S., Hackett, R. K., Estrada, H., "Evaluation of a Flipped Classroom in Mechanics of Materials", in American Society of Engineering Education Annual Conference \& Exposition, Proceedings of, Seattle, WA, 2015.

[11] Kellogg, S. "Technology Enabled Support Modules for the Inverted Entrepreneurial Classroom”, in American Society of Engineering Education Annual Conference \& Exposition, Proceedings of, Pittsburgh, PA, 2008.

[12] Dollar, A., “A Web-Based Statistics Course Used in an Inverted Classroom”, in American Society of Engineering Education Annual Conference \& Exposition, Proceedings of, Austin, TX, 2008.

[13] Bland, L., "Applying Flip/Inverted Classroom Model in Electrical Engineering to Establish Life-Long Learning", in American Society of Engineering Education Annual Conference \& Exposition, Proceedings of, Chicago, IL, 2008.

[14] Thomas, J.S., and Philpot, T.A., "An Inverted Teaching Model for a Mechanics of Materials Course", in American Society of Engineering Education Annual Conference \& Exposition, Proceedings of, San Antonio, TX, 2012.

[15] Papadopoulos, C., Santiago-Román, A., and Portela, G., "Work In Progress: Developing and Implementing an Inverted Classroom for Engineering Statics", In Frontiers in Education Conference (FIE), Proceedings of, Arlington, VA, 2010.

[16] Papdopoulos, C., and Santiago-Román, A., "Implementing an Inverted Classroom Model in Engineering Statics: Initial Results", in American Society of Engineering Education Annual Conference \& Exposition, Proceedings of, Louisville, KY, 2010. 
[17] Prince, M., "Does Active Learning Work? A Review of the Research", in Journal of Engineering EducationWashington, 93, pp223-232, 2004.

[18] Hmelo-Silver, C.E, “Problem-Based Learning: What and How Do Students Learn?", in Educational Psychology Review, 16(3), pp235-266, 2004.

[19] Barrows, H.S., "Problem-Based Learning in Medicine and Beyond: A Brief Overview", in New Directions for Teaching and Learning, 1996(68), pp3-12, 1996.

[20] Foot, H., and Howe, C., "The Psychoeducational Basis of Peer-Assisted Learning”, In K.J. Topping and S.W. Ehly, editors, Peer-Assisted Learning, pp27-43. Lawrence Erlbaum Associates, 1998.

[21] Johnson, D.W., and Johnson, R.T., "Learning Together and Alone: Overview and Meta-Analysis", in Asia Pacific Journal of Education, 22(1), pp95-105, 2002.

[22] Topping, K.J., and Ehly, S.W., "Peer-Assisted Learning”, Lawrence Erlbaum Associates, 1998. ISBN 9780805825022. URL http://books.google.com/books?id=UZv6grfgeF4C.

[23] Chi, M.T., and Wylie, R., “The ICAP Framework: Linking Cognitive Engagement to Active Learning Outcomes", in Educational Psychologist, 49(40), pp219-243, 2014.

[24] Chi, M.T., "Active-Constructive-Interactive: A Conceptual Framework for Differentiating Learning Activities," in Topics in Cognitive Science, 1, pp73-105, 2009.

[25] Hibbeler, R.C., Mechanics of Materials. $9^{\text {th }}$ ed. Prentice Hall, 2013

[26] Zhu, H., "Implementing Open-Ended Hands-on Design Projects throughout the Mechanical Engineering Curriculum", in American Society of Engineering Education Annual Conference \& Exposition, Proceedings of, New Orleans, LA, 2016.

[27] http://www.engageengineering.org/

[28] Sheppard, S.D., Macatangay, K., Colby, A. \& Sullivan, W.M., Educating Engineers: Designing for the Future of the Field. Jossey-Bass, pp 52, 2009.

[29] Chipman, S., Marshall, S. \& Scott, P., "Content Effects on Word Problem Performance: A Possible Source of Test Bias?”, in American Educational Research Journal. 28(4), pp897-915, 1991.

[30] National Academy of Engineering. New Directions in Engineering Excellence: Keeping Students Engaged. 2009.

[31] Bain, K., What The Best College Teachers Do. Harvard University Press. 2004.

[32] Campbell, P.B., Patterson, E.A., Busch Vishniac, I. \& Kibler, T., "Integrating Applications in the Teaching of Fundamental Concepts.", in American Society of Engineering Education Annual Conference \& Exposition, Proceedings of, Pittsburgh, PA, 2008. 